\title{
Bancada para portador de necessidades especiais
}

\section{Bench for people with special needs}

DOI: $10.46814 / \operatorname{lajdv} 3 n 4-062$

Recebimento dos originais: 01/05/2021

Aceitação para publicação: 31/06/2021

\author{
José Antonio castro Bartelega \\ Engenheiro Mecânico \\ Centro Paula Souza \\ Rua dos Andradas, 140 - São Paulo-SP \\ Joyce Maria de Sylva Tavares Bartelega \\ Engenheira Eletricista e de Segurança do Trabalho, Mestre em Física (UNESP) \\ Centro Paula Souza \\ Rua dos Andradas, 140 - São Paulo-SP \\ Luis Felipe dos Reis Montemor \\ Técnico em Mecânica \\ Centro Paula Souza \\ Rua dos Andradas, 140 - São Paulo-SP \\ Vinicius Hasmann dos Santos \\ Técnico em Mecânica \\ Centro Paula Souza \\ Rua dos Andradas, 140 - São Paulo-SP
}

\section{RESUMO}

Visto que a área de mecânica de produção não possui espaço para portadores de necessidades especiais, o que reflete na não-disposição de vagas, devido à falta de equipamentos que possibilitem a realização de seu respectivo serviço, surgiu a ideia da criação de uma "Bancada Ajustável", que por sua vez introduziria o portador de necessidades especiais no ramo da mecânica industrial, com foco principal no setor de ajustagem, incluindo-o profissional e socialmente, justapondo a lei $\mathrm{n}^{\mathrm{o}} 12.435$. Isso de forma a priorizar a utilização de materiais ecológicos e de baixo impacto ambiental, no caso aço - perfil vazado - e madeira plástica de procedência reciclável, tendo ainda uma estrutura simples e compacta, uma vez que sua área de ocupação é por volta de $1 \mathrm{~m}^{2}$ (um metro quadrado), o que influi na redução do consumo de matéria-prima. O projeto foi baseado na NBR 9050, visando ao conforto e à praticidade em sua utilização. De acordo com pesquisas de campo, conclui-se que o projeto é interessante, tanto para o funcionário quanto para a empresa. É valido ressaltar que a Bancada pode ser usufruída por funcionários em geral, sendo eles portadores de necessidades especiais ou não, de qualquer forma, proporcionando conforto e mobilidade.

Palavras-chave: Sustentabilidade. Mobilidade. Inovação.

\section{ABSTRACT}

Since the production mechanics area has no space for people with special needs, which reflects in the non-availability of vacancies, due to the lack of equipment which makes it possible to perform their respective service, the idea of creating an "Adjustable Bench" arose, which in turn would introduce the 
special needs bearer in the industrial mechanics field, focusing mainly on the adjustment sector, including him professionally and socially, juxtaposing law no. 12,435. This in order to prioritize the use of ecological and low environmental impact materials, in this case steel - hollow profile - and plastic wood from recyclable sources, also having a simple and compact structure, since its occupation area is around $1 \mathrm{~m}^{2}$ (one square meter), which influences in the reduction of raw material consumption. The project was based on the NBR 9050, aiming at comfort and practicality in its use. According to field research, it was concluded that the project is interesting, both for the employee and for the company. It is worth mentioning that the bench can be used by employees in general, whether they have special needs or not, in any way, providing comfort and mobility.

Keywords: Sustainability. Mobility. Innovation.

\section{INTRODUÇÃO}

A Bancada para Portadores de Necessidades especiais tem como função a incrementação dos equipamentos de trabalho em fábricas e unidades de ensino, voltados ao setor de produção e possibilita a introdução de portadores de necessidades especiais no ramo da mecânica industrial, com foco principal no setor de ajustagem, incluindo-o profissional e socialmente como garante a lei $\mathrm{n}^{\mathrm{o}} \underline{12.435}$, de 2011: “Art. $2^{\circ}$ I - a proteção social que visa à garantia da vida, à redução de danos e à prevenção da incidência de riscos, especialmente: a promoção da integração ao mercado de trabalho".

Possibilita também aos portadores de necessidades especiais maior independência e isonomia quanto à sociedade, tendo como consequência a redução do número de dependentes do benefício fundado na lei citada anteriormente: “Art. $2^{\circ} \mathrm{I}$ - (...) a garantia de 01 (um) salário-mínimo de beneficio mensal à pessoa com deficiência e ao idoso que comprovem não possuir meio de prover a própria manutenção ou de tê-la provida por sua família”.

Viabilizou-se conforme o tempo disponível decorrente para a conclusão, priorizando a utilização de elementos ecologicamente corretos como madeira plástica de procedência reciclável, e uma estrutura que não exige elevada manutenção, reduzindo gastos e dando-a maior acessibilidade. É válido ressaltar que abrange as normas NBR 7195, NBR 9050 e NR 17.

\section{OBJETIVO}

Produzir um equipamento, ecologicamente correto, que possibilite aos portadores de necessidades especiais maior mobilidade e conforto em seus movimentos, o que lhes permiti uma inclusão, qualificação e realização profissional, justapondo as leis que lhes permitem tais direitos, assim inferindo na disposição de vagas para portadores de necessidades especiais, como garante a lei $n^{\circ}$ 8.213: 
LEI Nº 8.213, DE 24 DE JULHO DE 1991, lei de contratação de Deficientes nas Empresas. Lei 8213/91, lei de cotas para portadores de necessidades especiais dispõe sobre os Planos de Benefícios da Previdência, outras providências na contratação.

Art. 93 - a empresa com 100 ou mais funcionários está obrigada a preencher de dois a cinco por cento dos seus cargos com beneficiários reabilitados, ou pessoas portadoras de deficiência, na seguinte proporção:

- $\quad$ Até 200 funcionários..................... 2\%

- $\quad$ De 201 a 500 funcionários............ 3\%

- De 501 a 1000 funcionários......... 4\%

- $\quad$ Acima de 1001 funcionários.......... 5\%

As empresas que preenchem essa parcela de cargos, majoritariamente, empregam pessoas reabilitadas, quando muito, limitam os Portadores de necessidades (...) ao setor administrativo, por falta de equipamentos adequados.

\section{FUNDAMENTAÇÃO TEÓRICA}

Como base para desenvolver este projeto, utilizamos várias normas e leis que nos foram pertinentes, sendo elas NBR 9050, NBR 7195, NR 17, Lei n 8.213 e Lei ${ }^{\circ} 12.435$.

A NBR 9050 serviu-nos como base para agregar conforto e mobilidade em nossa bancada, uma vez que regulariza as dimensões mínimas e máximas do local de trabalho, para que o portador de necessidades especiais possa se movimentar com facilidade e conforto.

A NBR 7195 agregou segurança durante a execução de tarefas. É responsável por regularizar as cores para segurança como, por exemplo, o artigo 3.1.2, no qual é citada a cor alaranjada, que utilizamos na bancada, para indicar perigo em partes móveis que podem ocasionar desde lesões simples até as que limitam a mobilidade do trabalhador.

A NR 17 nos foi útil para tornarmos a bancada ergonomicamente correta, uma vez que estabelece parâmetros que permitem a adaptação das condições de trabalho às características psicofisiológicas dos trabalhadores, de modo a proporcionar o máximo de conforto, segurança e desempenho, justapondo os itens $n^{\circ} 17.3$ e 17.4 desta norma.

A Lei $n^{\circ} 8.213$ responsável pela motivação da equipe para a elaboração de um projeto que visa à resolução da problemática apresentada pela respectiva lei.

A Lei $n^{\circ} 12.435$ também nos foi motivadora, pois traz consigo objetivos de integração dos portadores de necessidades especiais no mercado de trabalho. 


\section{DESENVOLVIMENTO}

\subsection{DESCRIÇÃO METODOLÓGICA}

Para a elaboração desse projeto, utilizamos como campo de pesquisa algumas empresas, oficinas, bem como entrevistas com algumas pessoas. Durante as visitas nas empresas, observamos que não havia portadores de necessidades especiais trabalhando no ramo da mecânica industrial devido à falta de equipamentos apropriados que visem ao conforto e à mobilidade do trabalho. Em relação às pessoas entrevistadas, uma nos despertou atenção quando nos afirmou que tinha intenção de exercer a profissão de técnico em mecânica, mas a sua deficiência o impossibilitava e que, se houvesse equipamentos apropriados nas empresas, executaria com êxito este trabalho. A partir de tais conhecimentos adquiridos, iniciamos uma pesquisa na web, que confirmou a não disposição de equipamentos e vagas. Constatados tais fatos, demos início ao projeto.

Buscando tornar o projeto ainda mais ecológico, surgiu a ideia da implementação da madeira plástica (procedência reciclável), um recurso ecologicamente correto e barato. Durante a execução, deparamos com o seguinte problema: como sua produção é mais artesanal, não se tinha valores de resistência à compressão, tração e dureza. Dirigimo-nos então a um professor da FEG (UNESP Guaratinguetá) para conseguirmos realizar os devidos ensaios. A partir de então, focamos em sua estrutura, a qual passou por 03 (três) remodelagens até a atual, para que se houvesse um maior aproveitamento de suas capacidades. O projeto, no âmbito físico, segue as normas NBR 9050 e 7195 , garantindo o direito trabalhista, assim sanando a NR-17.

\subsection{RECURSOS NECESSÁRIOS}

Para elaboração desse projeto, utilizamos vários recursos de pesquisa, tais como livros e apostilas físicas e virtuais, computador /notebook, máquinas operatrizes, ferramentas e instrumentos mecânicos bem como os materiais de consumo como orçamentos, placas metálicas, tarugos, madeira reciclável (compósito) e metais reutilizados. Os materiais utilizados na confecção do projeto foram doados pela Fazenda Esperança, fabricante da madeira plástica, e pela Etec. Prof. Alfredo de Barros Santos, que cedeu os perfis de aço vazado.

Como componentes principais foram utilizados $6000 \mathrm{~mm}$ (6 metros) de aço perfil vazado $60 \mathrm{x}$ 60; 7000 mm (7 metros) de madeira plástica 200 x 40; Motor Elétrico Monofásico de 1/4 cv, 1700 RPM e redução $25 / 1$.

\subsection{CRONOGRAMA}

- Definição do grupo e pesquisa do tema: 07 a 15 de fevereiro.

- Definição do tema: 15 a 18 de fevereiro. 
- Pesquisa de Normas e Leis relacionadas ao tema: 19 a 26 de fevereiro.

- Croqui do projeto: 29 de fevereiro a 28 de março.

- Definição do Projeto: 21 de março a 04 de abril.

- Pesquisas de materiais: 28 de março a 02 de maio.

- Pesquisa de mercado: 25 de abril a 09 de maio.

- Cálculos e Ensaios: 04 de abril a 06 de junho.

- Definição de materiais: 11 de abril a 25 de abril.

- Montagem tridimensional: 25 de abril a 02 de maio.

- Execução do projeto: 11 de abril a 13 de junho.

- Desenvolvimento teórico: 16 de fevereiro a 18 de junho.

\subsection{RESULTADOS E DISCUSSÕES}

Quanto ao projeto como um todo, obtivemos seu funcionamento com total e pleno êxito e uma excelente aceitação por parte das empresas e dos trabalhadores. Divulgamos a Bancada para o portador de necessidades especiais em feiras como a FETEPS visando demonstrar à sociedade e ao próprio portador a possibilidade de desenvolver um equipamento, relativamente simples, que satisfaz as necessidades humanas quanto ao trabalho na indústria e quanto à profissionalização.

Espera-se, ainda, que o projeto possa dar um impulso nos estudos voltados a ferramentas e equipamentos para esse mercado, que mesmo hoje no século XXI, o século da modernidade, encontrase tão esquecido e desatualizado.

Quanto à Madeira Plástica, obtivemos excelentes resultados. Os corpos de prova ensaiados se mostraram frágeis quanto à tração, resistência máxima por volta de $200 \mathrm{~kg}$, porém muito resistentes à compressão, algo em torno de 12 toneladas, características perfeitas para as funções empregadas.

\section{CONCLUSÕES}

O projeto, se realizado em grande escala, poderá criar uma elevada redução no consumo de recursos naturais, uma vez que incentiva a utilização de estruturas compactas e simples, e a aplicação de compósitos/aglomerados, de procedência reciclável, para a produção e o consumo industrial, tendo em mente ainda a integração de portadores de necessidades especiais e a garantia de conforto a seus usuários. Devido a sua estrutura compacta, não gera elevados custos, tornando-a mais acessível a todos. 


\section{REFERÊNCIAS}

REFERENCIAS

ASSOCIAÇÃO BRASILEIRA DE NORMAS TÉCNICAS. NBR 9050: Acessibilidade a edificações, mobiliário, espaços e equipamentos urbanos.

ASSOCIAÇÃO BRASILEIRA DE NORMAS TÉCNICAS. NBR 7195: Cores para segurança.

BEER, F. P.; JOHNSTON, E. R.; DEWOLF, J. T. Resistência dos materiais - mecânica dos materiais. 4 ed. São Paulo: McGraw-Hill, 2006. 758p.

Leis Ordinárias. Disponível em: <http://www.planalto.gov.br/ccivil_03/_Ato20112014/2011/Lei/L8213.htm>. Acesso em: 19. Fev de 2012

Leis Ordinárias. Disponível em: <http://www.planalto.gov.br/ccivil_03/_Ato20112014/2011/Lei/L12435.htm>. Acesso em: 23. Fev de2012

MELCONIAN, S. Elementos de Máquinas. 7 ed. São Paulo: Érica, 2006. 358p.

. Mecânica técnica e resistência dos materiais. 13. ed. São Paulo: Érica, 2003. 360p. 


\section{APÊNDICE}

\section{APENDICE}

\section{Resultados do Ensaio De Tração}

\begin{tabular}{|c|c|c|c|c|}
\hline & Força Max. & Tensão Max. & Deslocamento Max. & Força de Ruptura \\
\hline Unidade & $\mathrm{N}$ & $\mathrm{kPa}$ & $\mathrm{mm}$ & $\mathrm{N}$ \\
\hline $\mathrm{L} 1$ & 2319,82 & 17029,0 & 2,67844 & 2240,46 \\
\hline Média & 2579,99 & 19364,0 & 3,04612 & 2467,09 \\
\hline Desvio Padrão & 367,929 & 3302,19 & 0,51997 & 320,503 \\
\hline Máximo & 2840,15 & 21699,0 & 3,41379 & 2693,72 \\
\hline Mínimo & 2319,82 & 17029,0 & 2,67844 & 2240,46 \\
\hline
\end{tabular}

\section{Gráfico de Tensão e Deformação}

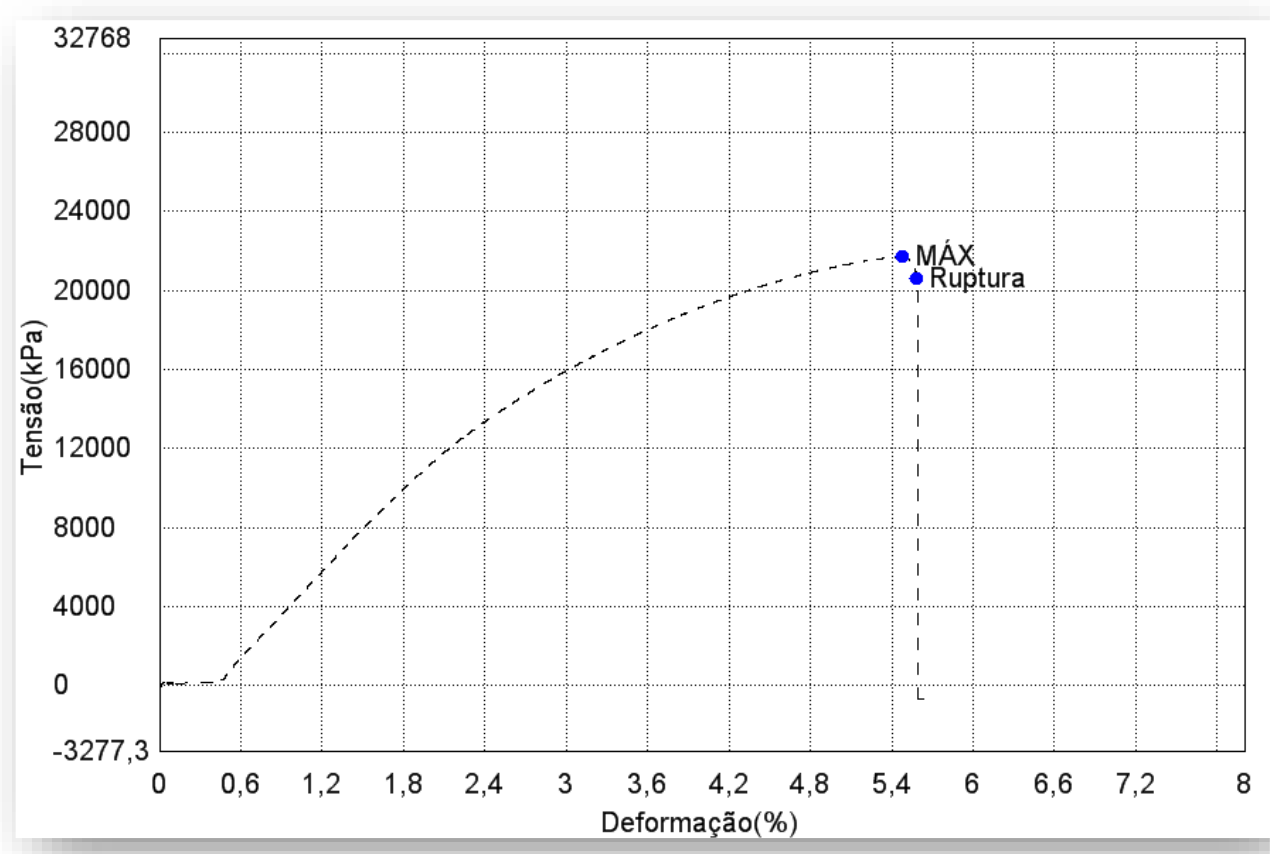

Resultados do Ensaio de Compressão 


\begin{tabular}{|c|c|c|}
\hline & Força Max. & $\begin{array}{c}\text { Força de } \\
\text { Ruptura }\end{array}$ \\
\hline Parâmetros & Cálculo de áreas & Sensibilidade: 10 \\
\hline Unidade & $\mathrm{N}$ & $\mathrm{N}$ \\
\hline Média & 120000 &.-- \\
\hline
\end{tabular}

\section{Gráfico de Força e Percurso}

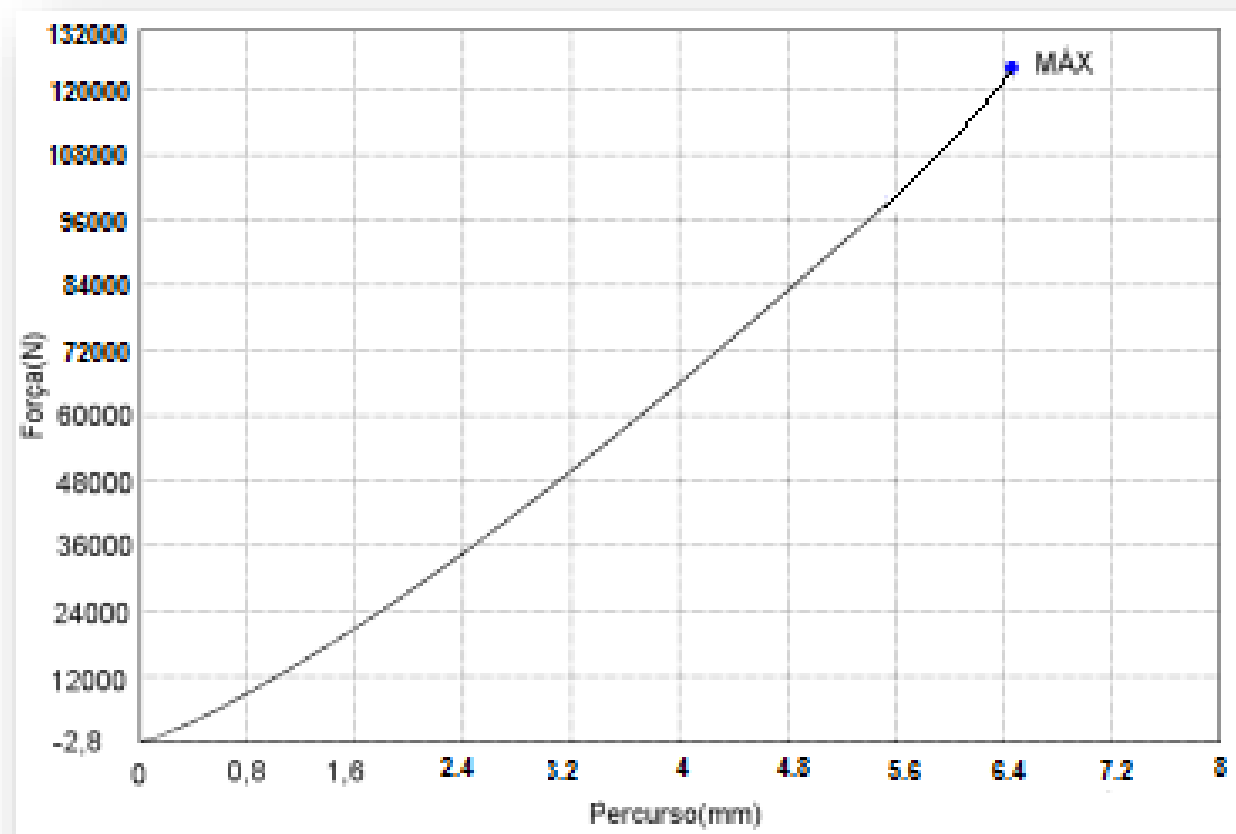

Ferramentas e Instrumentos:

Máquina universal - tração: $50 \mathrm{KN} /$ Máquina universal - Compressão: $200 \mathrm{KN}$

Capacidade trabalhada: respectivamente $50 \mathrm{KN}$ e $200 \mathrm{KN}-1$ (um) milímetro por minuto.

Corpos de Provas: Madeira Plástica (Aglomerado)

\section{Imagens da Pesquisas/Elaboração}




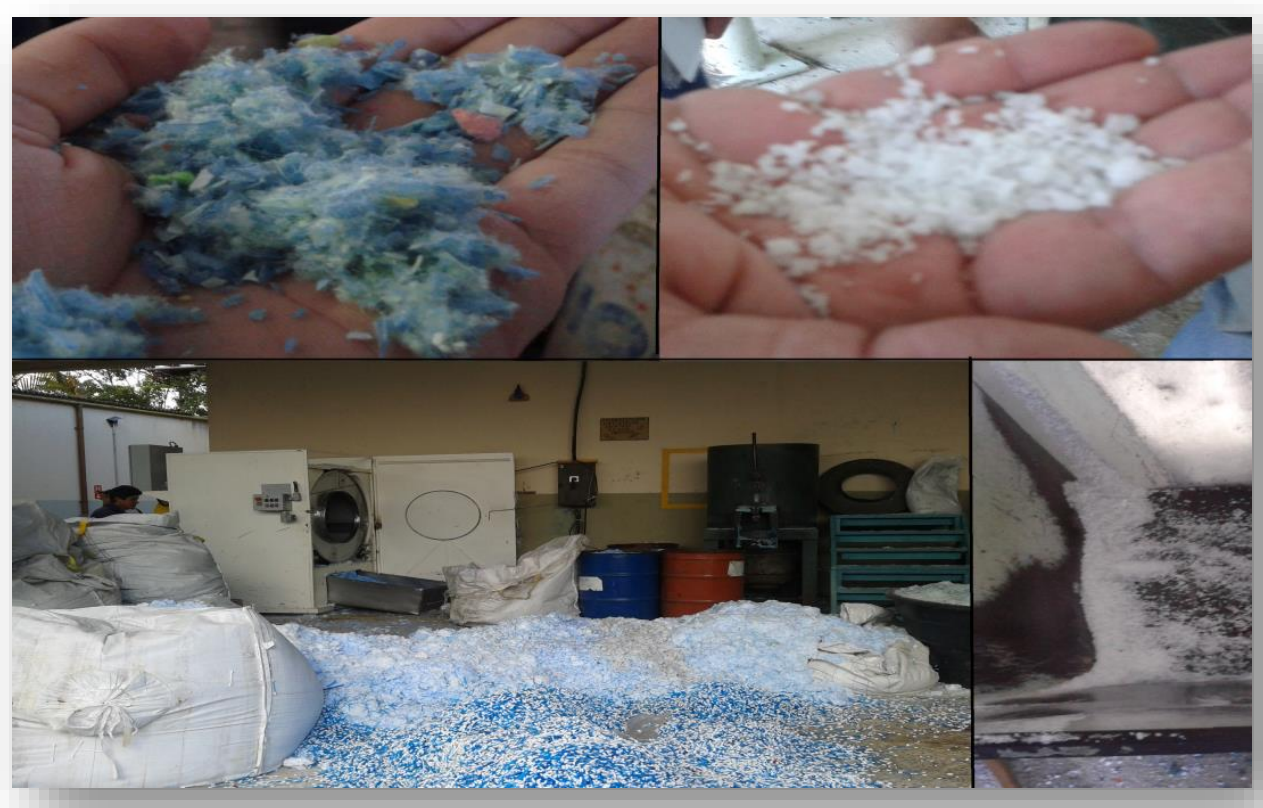

\section{Matéria-prima - Madeira Plástica}

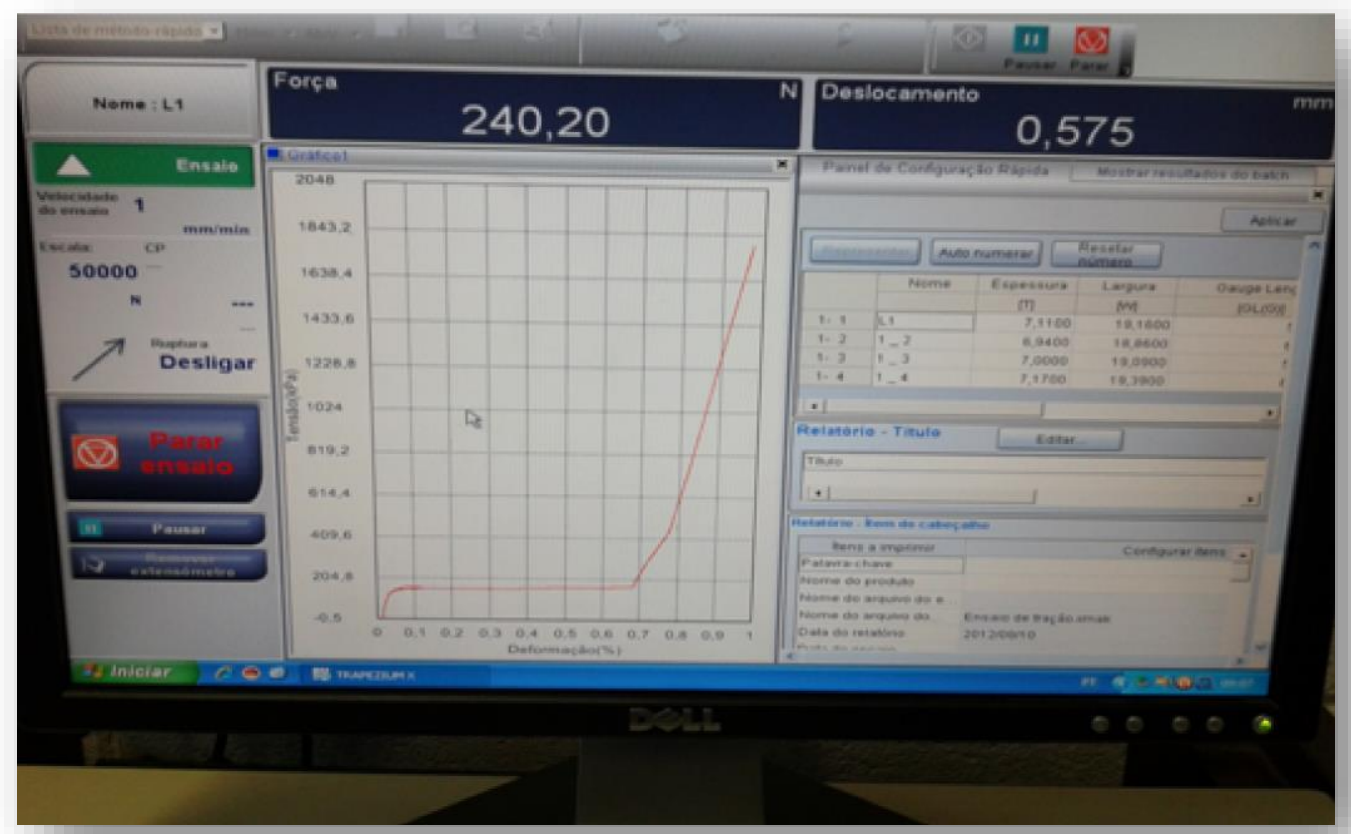

\section{Execução do Ensaio de Tração - Madeira Plástica}

\section{ANEXOS}

Seguem anexados trechos de Leis e Normas que foram pertinentes à execução e elaboração do projeto. 
NBR 7195:

1 Objetivo

Esta Norma fixa as cores que devem ser usadas para prevenção de acidentes, empregadas para identificar e advertir contra riscos.

\section{Condições gerais}

2.1 A indicação dos riscos por meio de cores não dispensa o emprego de outras formas de prevenção de acidentes.

2.2 Com exceção das cores verde, branca e preta, as demais cores padronizadas nesta Norma não devem ser utilizadas na pintura do corpo de máquinas.

3 Condições específicas

\section{1 $\operatorname{Cores}(1)$}

As cores adotadas nesta Norma são as seguintes:
a) vermelha;
b) alaranjada;
c) amarela;
d) verde;
e) azul;
f) púrpura;

\subsubsection{Alaranjada}

É a cor empregada para indicar "perigo". É utilizada, por exemplo, em:

a) partes móveis e perigosas de máquinas e equipamentos;

b) faces e proteções internas de caixas de dispositivos elétricos que possam ser abertas;

c) equipamentos de salvamento aquático, como boias circulares, coletes salva-vidas, flutuadores salva-vidas e similares.

NBR 9050:

\subsection{Alcance manual}




\subsubsection{Dimensões referenciais para alcance manual}

As figuras 8 a 10 exemplificam as dimensões máximas, mínimas e confortáveis para alcance manual frontal.

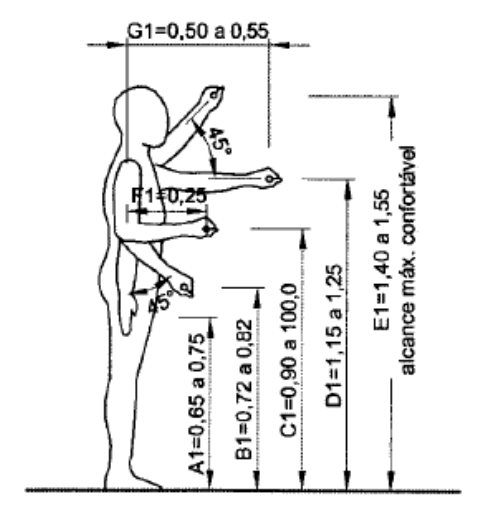
A1 = Altura do centro da măo estendida ao longo do eixo longitudinal do corpo
$\mathrm{B} 1=$ Altura do piso até o centro da måo com antebraço formando ângulo de $45^{\circ} \mathrm{com} \circ$ tronco
C1 = Altura do centro da mão com antebraço em ângulo de $90^{\circ}$ com o tronco
D1 = Altura do centro da mão com braço estendido paralelamente ao piso
E1 = Altura do centro da mão com o braço estendido formando $45^{\circ} \mathrm{com}$ o piso $=$ alcance máximo confortável
$\mathrm{F} 1$ = Comprimento do antebraço (do centro do cotovelo ao centro da mão)
G1 = Comprimento do braço na horizontal, do ombro ao centro da mão

\section{Figura 8 - Alcance manual frontal - Pessoa em pé}

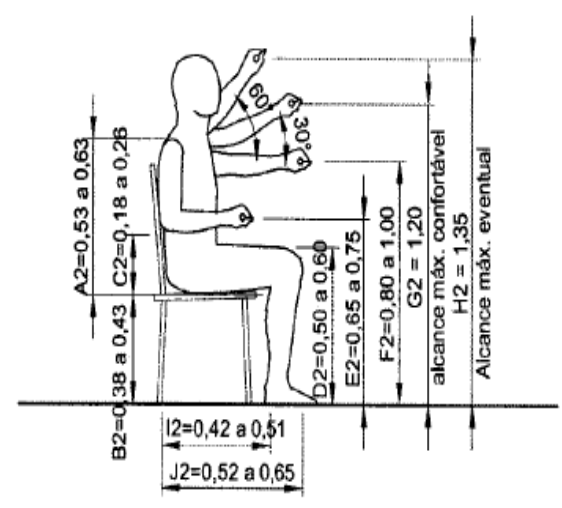

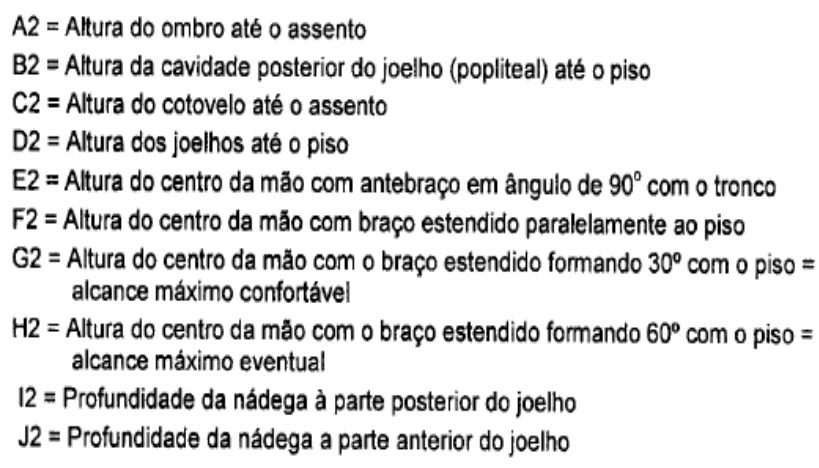

Figura 9 - Alcance manual frontal - Pessoa sentada 

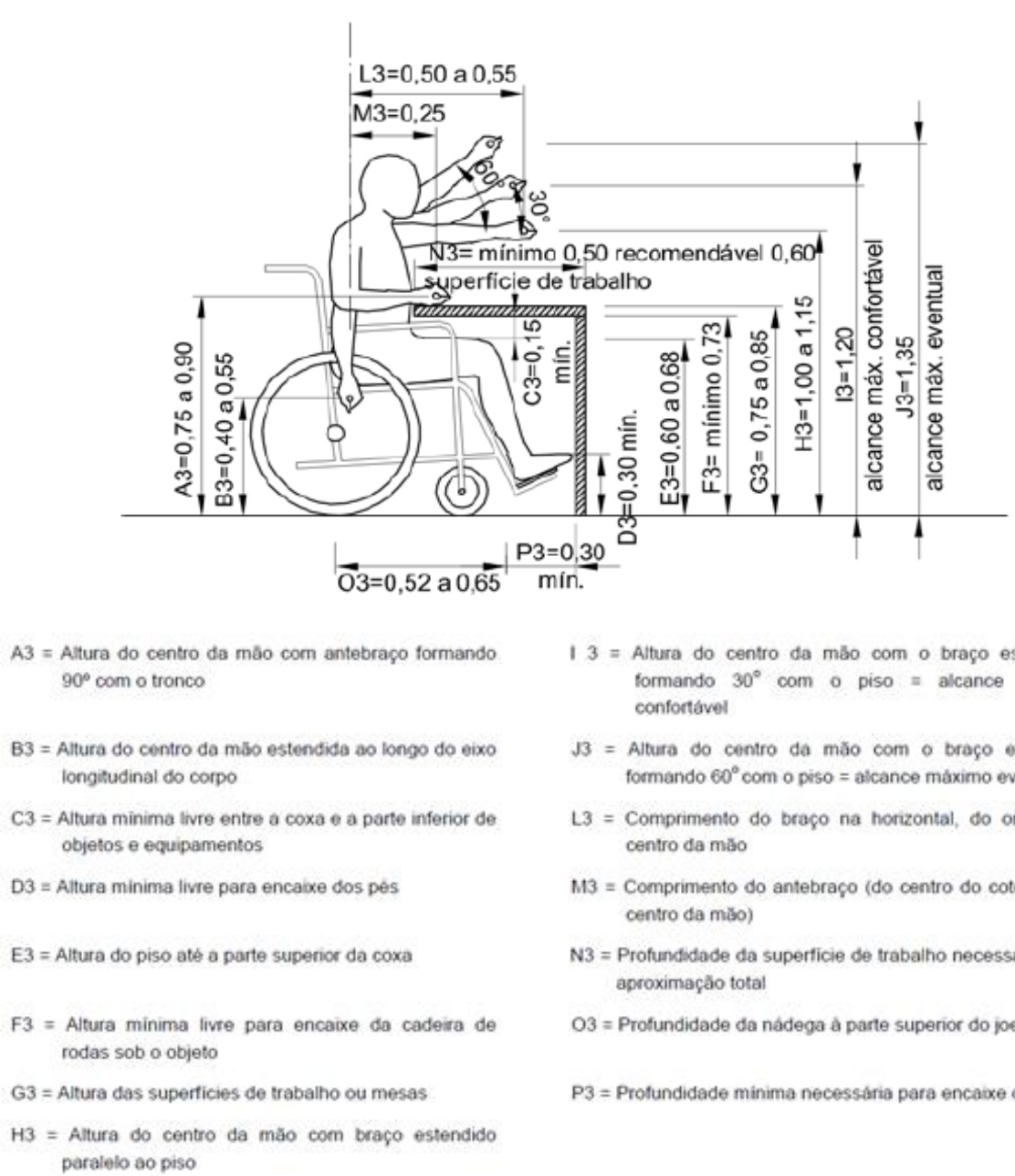

H3 = Altura do centro da măo com braço estendido paralelo ao piso

$\sqrt{3}=$ Altura do centro da mão com o braço estendido formando $60^{\circ} \mathrm{com}$ o piso = alcance máximo eventual

$\mathrm{L} 3=$ Comprimento do brą̧o na horizontal, do ombro ao centro da măo

$M 13$ = Comprimento do antebraço (do centro do cotovelo ao centro da măo)

N3 = Profundidade da superficie de trabalho necessána para aproximaçăo total

O3 = Profundidade da nádega à parte superior do joeltho

P3 = Profundidade minima necessadria para encaixe dos pés

Figura 10 - Alcance manual frontal com superfície de trabalho - Pessoa em cadeira de rodas

\subsection{3 - Superfície de Trabalho}

As superficies de trabalho necessitam de altura livre de no minimo $0.73 \mathrm{~m}$ entre o piso e a sua parte inferior, e altura de $0,75 \mathrm{~m}$ a $0,85 \mathrm{~m}$ entre o piso e a sua superficie superior. A figura 12 apresenta no plano horizontal as áreas de alcance em superficies de trabalho, conforme abaixo:

a) $\mathrm{A} 1 \times \mathrm{A} 2=1,50 \mathrm{~m} \times 0,50 \mathrm{~m}=$ alcance máximo para atividades eventuais:

b) $B 1 \times B 2=1,00 \mathrm{~m} \times 0,40 \mathrm{~m}=$ alcance para atividades sem necessidade de precisão;

c) $C 1 \times C 2=0,35 \mathrm{~m} \times 0,25 \mathrm{~m}=$ alcance para atividades por tempo prolongado.

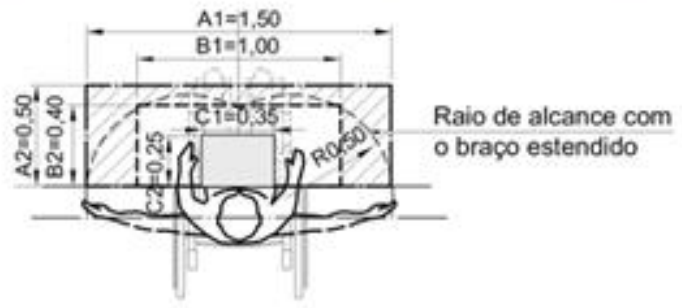

12 - Superfície de Trabalho 
NR 17:

LATIN AMERICAN

\subsection{Mobiliários do Posto de Trabalho}

17.3.1 Sempre que o trabalho puder ser executado na posição sentada, o posto de trabalho deve ser planejado ou adaptado para esta posição. (117.006-6/11).

17.3.2 Para trabalho manual sentado ou que tenha de ser feito em pé, as bancada, mesas, escrivaninhas e os painéis devem proporcionar ao trabalhador condições de boa postura, visualização e operação e devem atender aos seguintes requisitos mínimos:

a) Ter altura e características da superfície de trabalho compatíveis com o tipo de atividade, com a distância requerida dos olhos ao campo de trabalho com a altura do assento (117.007$4 / 12)$.

b) Ter área de trabalho de fácil alcance e visualização pelo trabalhador (117.008-2/12).

c) Ter características que possibilitem posicionamento e movimentação adequados dos segmentos corporais (117.009-0/12).

\subsection{Equipamentos dos postos de trabalho}

17.4.1 Todos os equipamentos que compõem um posto de trabalho devem estar adequados às características psicofisiológicas do trabalho a ser executado.

LEI $n^{\circ}$ 8.213:

Art. 93 - A empresa com 100 ou mais funcionários está obrigada a preencher de dois a cinco por cento dos seus cargos com beneficiários reabilitados, ou pessoas portadoras de deficiência, na seguinte proporção:

- Até 200 funcionários $2 \%$

- De 201 a 500 funcionários........... 3\%

- De 501 a 1000 funcionários......... 4\%

- Acima de 1001 funcionários.......... 5\%

\section{LEI n ${ }^{\circ}$ 14.435:}

Art. $2^{\circ} \mathrm{I}$ - a proteção social que visa à garantia da vida, à redução de danos e à prevenção da incidência de riscos, especialmente: c) a promoção da integração ao mercado de trabalho. 